\title{
Drug Utilization and Rationality of Antiepileptic Drugs in Epilepsy in a Tertiary Care Teaching Hospital of Dehradun
}

\author{
Sarita $^{1}$, Neeraj Kumar ${ }^{2}$, Sudhakar kaushik ${ }^{3}$, Preeti Kothiyal ${ }^{4}$ \\ Correspondence Author \\ Sarita (M. Pharm S, G, R, R, U Dehradun Uttrakhand) \\ Co Author \\ Neeraj Kumar (Assistant Professor $S, G, R, R, U$ Dehradun Uttrakhand) \\ Sudhakar kaushik (Assistant Professor $S, G, R, R, U$ Dehradun Uttrakhand) \\ Preeti Kothiyal (Professor $S, G, R, R, U$ Dehradun Uttrakhand) \\ Email-saritarawat700@gmail.com
}

\begin{abstract}
To evaluate the drug utilization pattern and rationality of antiepileptic drugs in epilepsy in a tertiary care teaching hospital of Dehradun. The study carried out on 110 patients show that most of the epilepsy patient has generalized tonic-clonic epilepsy followed by simple partial, complex partial and absence type of epilepsy. Number of male patient is more than number of female patient having antiepileptic drugs in epilepsy. Polytherapy is more used as compared to monotherapy, antiepileptic drugs used as polytherapy are used in 2 drug combination, 3 drug combination and more than 3 drug combination for the treatment of epilepsy. First generation antiepileptic is more prescribed as compared to second generation antiepileptic drugs for the treatment of epilepsy. Phenytoin was most commonly prescribed antiepileptic drugs for epilepsy in both monotherapy and polytherapy. Finding of the study suggested that subjects using antiepileptic drug therapy for epilepsy for below 18 years are less as compared to above 18 years. The study also revealed that rationality among the maximum subjects receiving antiepileptic drugs polytherapy for epilepsy was found rational. Polytherapy is mostly used in the terms of treatment with antiepileptic drugs in epilepsy. Rationality of antiepileptic drugs in epilepsy was followed maximally. Phenytoin was prescribed more commonly in both monotherapy and polytherapy.
\end{abstract}

Key Words: Antiepileptic drugs, monotherapy, polytherapy, rationality

\section{INTRODUCTION}

Epilepsy is defined as a condition characterized by recurrent (two or more) epileptic seizures, epilepsy is a constant neurological disorder of the brain which requires elongated characterized management. ${ }^{1}$ It is characterized by the persistent manifestation of spontaneous attack owing to neuronal hyperactivity in the mind. ${ }^{[2]}$ About $1 \%$ of world population suffers from epilepsy. With today's available antiepileptic drugs, about one third of seizures affected individuals can be controlled and about $8 \%$ may get profit from epileptic surgery treatment. The remaining of epilepsy patient cannot treat by any available therapy. ${ }^{[3]}$ Selection of most appropriate antiepileptic drugs depends on classification of seizure and age of the patients. Normally monotherapy is the first line of treatment for epilepsy, as it has less drug interaction and side effects, lower cost, better tolerability, medication adherence and quality of life. ${ }^{[4]}$ Around $70 \%$ of adults having new-onset epilepsy suffer from partial (focal) seizures. In the most common cases, the reason is unidentified. Some other cause are stroke, head trauma, alcohol, neurodegenerative disease, static encephalopathy, brain tumors and infection report for remain cases. While cerebrovascular causes are more general in the elderly, the cause is still unidentified in patients who are 65 years of age or older. ${ }^{[5]}$ The incidence in urban countries is around 50 per 100,000 per annum and is maximum in childhood and elderly. The prevalence is around $0.5-1 \%$.

Epilepsy must be regard as a symptom of a primary condition and a whole diagnosis includes confirmation of the epileptic nature of the seizures, the epilepsy condition and the aetiology. Epileptic seizures are diagnosed clinically from the descriptions of the patient and an eyewitness, videos of seizures and electroencephalograph (EEG) videotelemetry can also be useful. Awareness with the different seizure types is essential for both differential diagnosis and proper management. ${ }^{[6]}$

\section{MATERIALS AND METHOD}

It was a prospective and observational study. Subjects were randomly selected for the study from the following wards of the hospital- Neurology, pediatrics, psychiatric and general medicine. All the data regarding drug utilization pattern and rationality of antiepileptic drugs were interviewed and filled in data collection form and questionnaire. All subjects were interviewed on the basis 


\section{International Journal of Research in Advent Technology, Vol.7, No.1, January 2019 E-ISSN: 2321-9637 Available online at www.ijrat.org}

of a self structured questionnaire and data were taken from patient profile file in self structured patient profile form. And the study was designed to be of six months. The objectives of the study include:

- To determine drug utilization pattern in the treatment with antiepileptic drugs in epilepsy.

- To determine drug interaction of antiepileptic drugs.

- To assess most commonly prescribed antiepileptic drugs.

- To assess no. of seizure occurred in different age group.

- To assess Rationality of drug therapy of antiepileptic drugs in epilepsy.

The epileptic subjects who were coming to the Shri Mahant Indiresh hospital were selected for the study. Data collection form and questionnaire were self prepared.

$>\quad$ Data collection form divided into 2 parts.

- Part I-Include data about- chief complain, medication history and previous allergies.

- Part II- Include data about- laboratory data, side effect, present medication, drug interaction and discharge summary.

$>$ Structured questionnaires divided into 2 parts.

- Part I- Includes data about- sociodemographics data.

- Part II- Questions regarding- epilepsy type, no of fits according to age group, etiology, drug interaction and treatment status

Statistical calculations were carried out in MS Excel using descriptive analysis. Drug interactions were carried out by using Micromedex solution software. Rationality assessments of AEDs in epilepsy were analyzed by global standard of ILAE (International League against Epilepsy) according to their mechanism of action and drug class.

\section{RESULT}

As epilepsy is a condition characterized by recurrent (two or more) epileptic seizures, epilepsy is a constant neurological disorder of the brain which requires elongated characterized management. It is characterized by the persistent manifestation of the spontaneous attack owing to neuronal hyperactivity in the mind. Selection of the most appropriate antiepileptic drugs depends on the classification of seizure and age of the patient. To study drug utilization and rationality of antiepileptic drugs in epilepsy in a tertiary care teaching hospital of Dehradun
In this study subjects were interviewed on the basis of a self structured questionnaire and data collection form. The questionnaire and data collection form include data regarding demographic, symptoms, epilepsy type, history of seizure and treatment used for epilepsy.

Related to the demographic characteristic of epileptic patients, the study revealed that $56 \%$ were male while $44 \%$ were female subjects. This was similar with the study of Chen L.C et al. ${ }^{[7]}$ who said among all subjects, $64.75 \%$ subjects were males and $35.25 \%$ subjects were females.

As regards to the antiepileptic drug therapy used in epilepsy, the study revealed that more number of participants is on polytherapy $(56.37 \%)$ as compared to monotherapy $(43.63 \%)$. This was differ from the study of Patel P.M et al ${ }^{[1]}$ who said that monotherapy of antiepileptic was most commonly used $(70.6 \%)$ in the treatment of epilepsy.

Regarding to type of epilepsy this study revealed that among 110 subjects generalized tonic clonic epilepsy $37.27 \%$ is most common in all age group followed by simple partial epilepsy $32.73 \%$ and complex partial epilepsy $31.82 \%$. This study was similar with the study of Patel et al. ${ }^{[1]}$ who said that $29.78 \%$ subjects having generalized tonic clonic seizure.

Related to prescribing of antiepileptic drugs according to first and second generation this study stated that first generation antiepileptic drugs $60.49 \%$ (which include phenytoin $66.35 \%$, valproate, $21.16 \%$, carbamazepam $10.57 \%$, Phenobarbital (1.92\%) were prescribed higher as compared to second generation antiepileptic drugs i.e $39.51 \%$ (which include levetiracetam $69.12 \%$, diazepam $2.94 \%$, clobazam $8.82 \%$, lorazepam $16.18 \%$, clonazepam $2.94 \%$ ). This study was similar with Patel et al. ${ }^{[1]}$ Who said that conventional antiepileptic (78.95\%) were prescribed more frequently than newer antiepileptic (21.05\%) for epilepsy.

Regarding the most commonly prescribed antiepileptic drugs among 110 subjects in all type of epilepsy was found phenytoin $62.72 \%$. This study was similar to the study of Mathur $S$ et al. ${ }^{[3]}$ according to this study revealed that more frequently prescribed antiepileptic drug were phenytoin $60.41 \%$ for epilepsy.

Related to the antiepileptic drug combination used in the therapy of epilepsy treatment 2 drug combination $69.35 \%$ was most commonly used followed by 3 drug combination $19.35 \%$ and more than 3 drug combination $11.30 \%$. This study was found similar with Mathur et al. [3] according to this study revealed that number of patient receiving 2 drug combinations in epilepsy was $41.00 \%$ and number of patient receiving 3 drug combinations was $5.03 \%$ in poly therapy.

Out of 110 subjects $34(31 \%)$ was below 18 years and $76(69 \%)$ was above 18 years who was using antiepileptic drug therapy for epilepsy. This was found similar to 


\section{International Journal of Research in Advent Technology, Vol.7, No.1, January 2019 E-ISSN: 2321-9637 \\ Available online at www.ijrat.org}

Patel et al. ${ }^{[1]}$ according to this study revealed that among all 160 subjects $76.8 \%$ was found above 18 years and $8.8 \%$ was found below 18 years using antiepileptic drug therapy.

Related to the number of epileptic participants among 110 subjects, our study reveal that number of epileptic subjects found among 17 age group was 0-4 (9.09\%), 59 (9.09\%), 10-14 (7.30\%), 15-19 (13.63\%), 20-24 (7.30\%), 25-29 (6.36\%), 30-34 (6.36\%), 35-39 (8.18\%), 40-44 (3.635), $\quad 45-49(4.54 \%), 50-54(4.54 \%), 55-59$ (6.36\%), 60-64 (2.73\%), 65-69 (2.73\%), 70-74 (3.63\%), $74-79(0.90 \%)$ and 80 and above $(3.63 \%)$. Highest numbers of subjects were found in the age group of 15 $19(13.63 \%)$. This study was differ from the study of Hanssens $Y$ et al. ${ }^{[8]}$ according to this study revealed that highest no of epileptic subjects was found in the age group of 21-30 (35\%) followed by age group 14$20(34.2 \%)$.

In finding of drug interaction of antiepileptic drugs in epilepsy seen that among 110 subjects $1 \%$ of the patient were serious drug interaction, $22.60 \%$ were found monitor closely drug interaction $16.12 \%$ were found minor drug interaction and $59.76 \%$ were found no drug interaction. This study was similar to Ekstein $D$ et al. ${ }^{[9]}$ according to this study revealed that less numbers of drug interaction was found in antiepileptic drug therapy in epilepsy they refuge to reveal. They exact numbers.

Regarding to rationality assessment the study stated that out of 62 subjects receiving poly therapy, $82.10 \%$ found rational polytherapy of antiepileptic drugs and $12.90 \%$ found irrational polytherapy of antiepileptic drugs. This study was found similar with George J et al. ${ }^{[4]}$ according to this study revealed that out of 125 subjects, $64 \%$ was found to be rational and $36 \%$ of prescriptions were irrational.

\section{DISCUSSION AND FINDINGS OF THE STUDY}

This study finding has demonstrated that most of the epilepsy patient has generalized tonic-clonic epilepsy followed by simple partial, complex partial and absence type of epilepsy. Number of male patient is more than number of female patient having antiepileptic drugs in epilepsy. Polytherapy is more used as compared to monotherapy, antiepileptic drugs used as polytherapy are used in 2 drug combination, 3 drug combination and more than 3 drug combination for the treatment of epilepsy. First generation antiepileptic is more prescribed as compared to second generation antiepileptic drugs for the treatment of epilepsy. Phenytoin was most commonly prescribed antiepileptic drugs for epilepsy in both monotherapy and polytherapy. Finding of the study suggested that $31 \%$ subjects were below 18 years and $69 \%$ were above 18 years who were using antiepileptic drug therapy for epilepsy. The result also revealed that rationality assessment of the study stated that among the subjects receiving poly therapy, $82.10 \%$ found rational polytherapy of antiepileptic drugs and $12.90 \%$ found irrational polytherapy of antiepileptic drugs. In the drug interaction of antiepileptic drugs in epilepsy we found that among 110 subjects, $1 \%$ of the patient were serious drug interaction, $22.60 \%$ were found monitor closely drug interaction $16.12 \%$ were found minor drug interaction and $59.76 \%$ were found no drug interaction.

\section{CONCLUSION}

Polytherapy is mostly used in the terms of treatment with antiepileptic drugs in epilepsy. Rationality of antiepileptic drugs in epilepsy was followed maximally. Phenytoin was prescribed more commonly in both monotherapy and polytherapy.

\section{ACKNOWLEDGEMENT}

The authors are thankful to Shri Mahant Devendra Dass Ji Maharaj, Chairman,Shri Guru Ram Rai Education Mission,Dehradun,Uttarakhand,for providing necessary information and financial support.

\section{REFERENCES}

[1] Patel.P.M,; Shah A.M,; Gajjar M.B.(2016): Drug utilization pattern of antiepileptic Drug in tertiary Care Teaching Rural Hospital. National Journal of Physiology, Pharmacy and Pharmacology, 6(5) pp.458-463.

[2] Kumara P,; Saha L,; Neha, Vijayanti S,; Bhatia A,; Banerjee D,; Chakrabarti A.(2016): To evaluate the anti-kindling effects of allopregnanolone alone and its intraction with Sodium Valporate in pentylenetrazole induced kindling model. International Journal of Epilepsy, pp.68-74.

[3] Mathur S,; Sen S,; Rramesh L,; Mkumar S.(2010): Utlization Pattern of Antiepileptic Drug and Their Adverse Effects, In a Teaching Hospital. Asian Journal of Pharmaceutical and Clinical Research, 3(1), pp.55-59.

[4] George J,: Jose J,: Kulkarni D.A,: Pol R.R,: Shalavadi H.M,: Mangannavar V.C. (2016) : Evaluation of Drug Utilization and Analysis of AntiEpileptic drugs at Tertiary Care Teaching Hospital. Indian Journal of Pharmacy Practice, 9(3), pp.189194.

[5] Goldenberg M.M. (2010): Overview of drug used for epilepsy and seizure. P\&T, 35(7), pp.392-415.

[6] Hart Y.M. (2016): Diagnosis and management of epilepsy. Epilepsy, pp.1-7.

[7] Chen L.C,; Chen Y.F,; Yang L.L,; Chou M.H,; Lin M.F.(2000): Drug utilization pattern of antiepileptic drugs and traditional Chinese medicines in a general hospital in Taiwan- a phamaco-epidemiologic study. 


\section{Available online at www.ijrat.org}

Journal of clinical pharmacy and therapeutics, 25, pp.125-129.

[8] Hanssen Y,; Deleu D,; Balushi KA,; Hashars A.A,; Zakwanis I.A. (2002): Drug utilization pattern of anti-epileptic drugs a pharmacoepidemiologic study in Oman. Journal of clinical pharmacy and therapeutics, 27, pp.357-364.
[9] Ekstein D,; Tirosh M,; Eyal Y,; Eyal S.(2015): Drug interaction involving antiepileptic drugs: assessment of the consistency among three compendia and FDA- approved lables. Epilepsy and behavior, 44, pp.218-224.

\section{FIGURES}

Figure 1- Distribution of subjects on the basis of gender

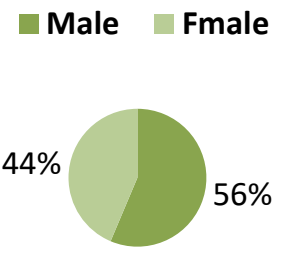

Figure 2- Distribution of subjects on the basis of age status

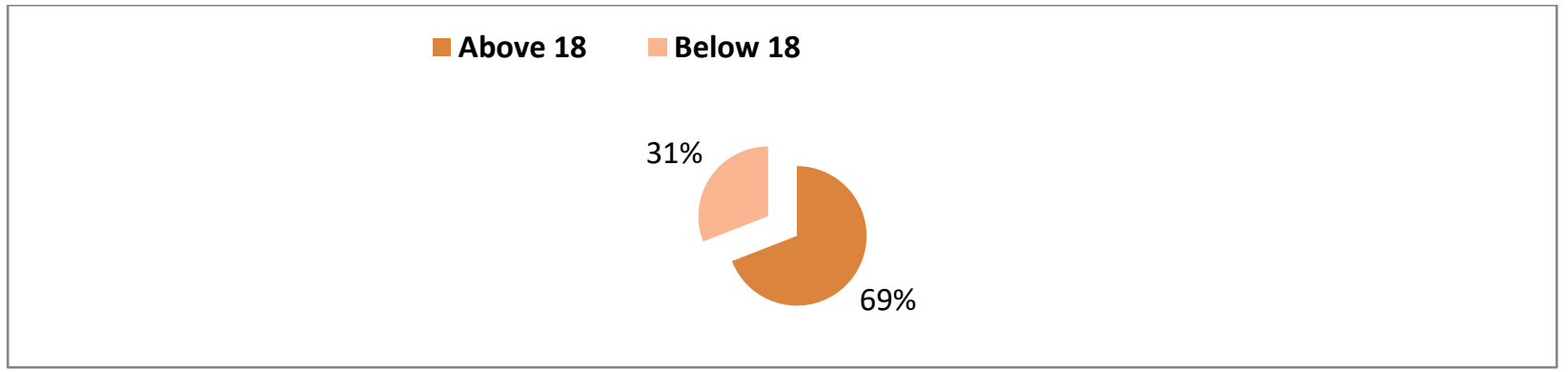

Figure 3- distribution of subjects on the basis of types of epilepsy

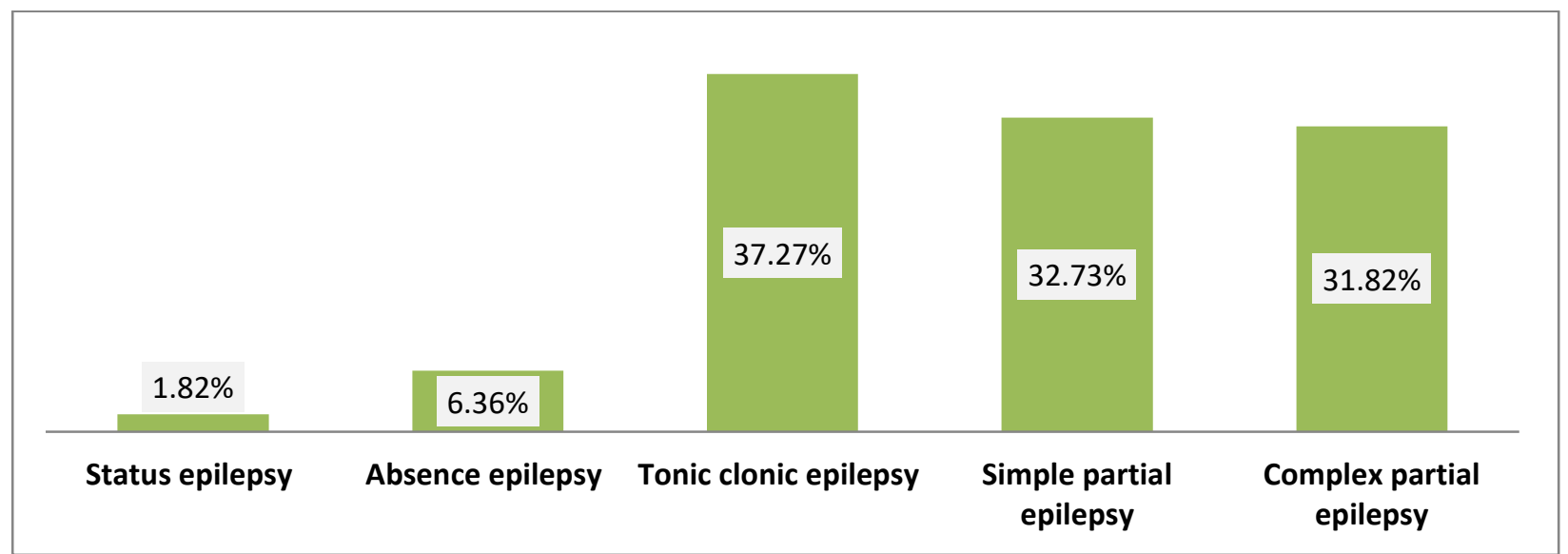

Figure 4- Distribution of prescribed antiepileptic drugs according to generation 
Available online at www.ijrat.org

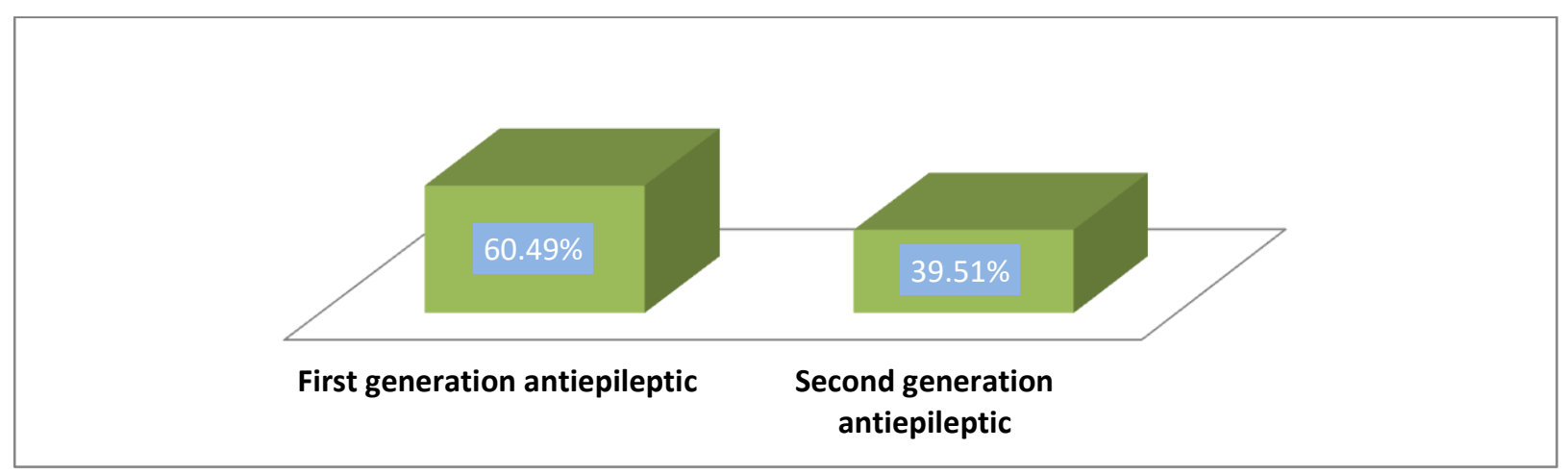

Figure 5- Distribution of antiepileptic drugs prescribed under first generation

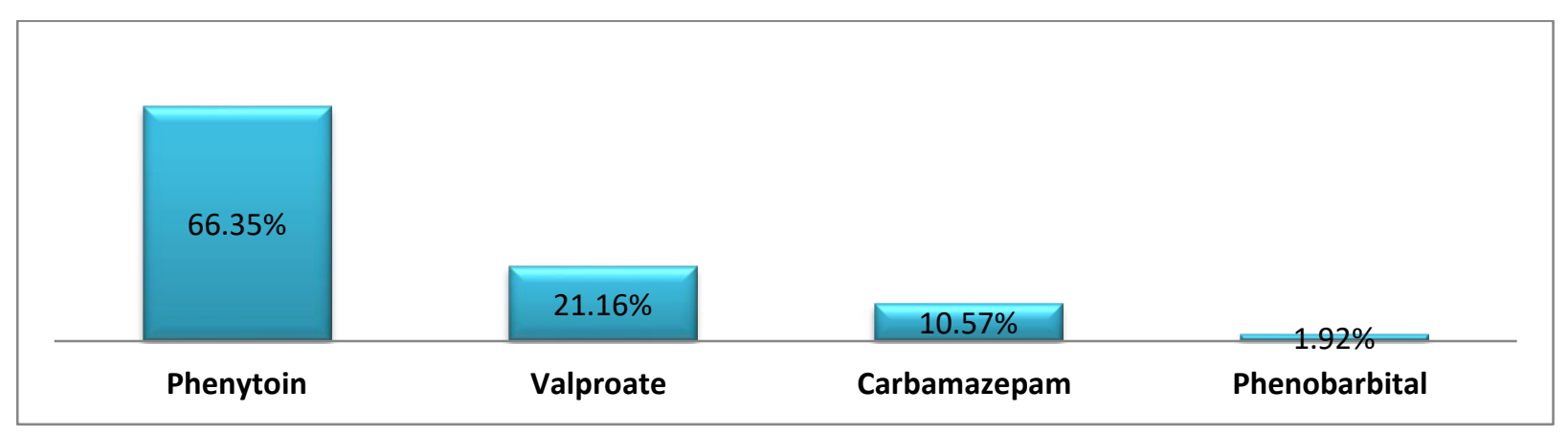

Figure 6- Distribution of antiepileptic drugs prescribed under second generation

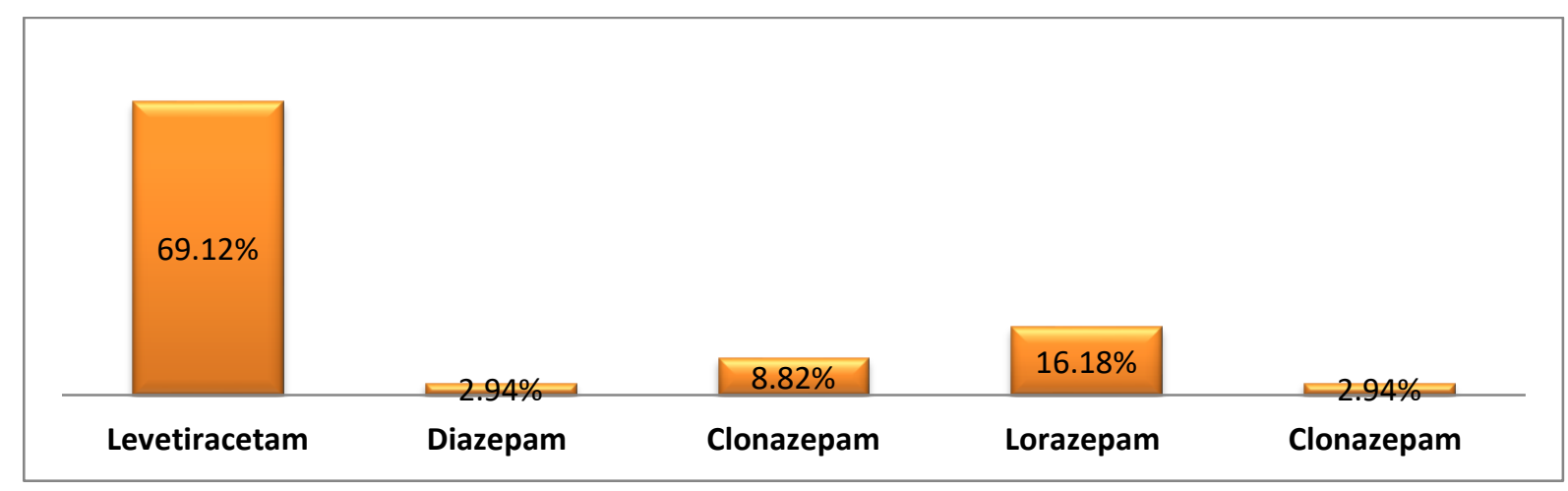

Figure 7- Distribution of antiepileptic drugs according to monotherapy and polytherapy 
International Journal of Research in Advent Technology, Vol.7, No.1, January 2019 E-ISSN: 2321-9637

Available online at www.ijrat.org

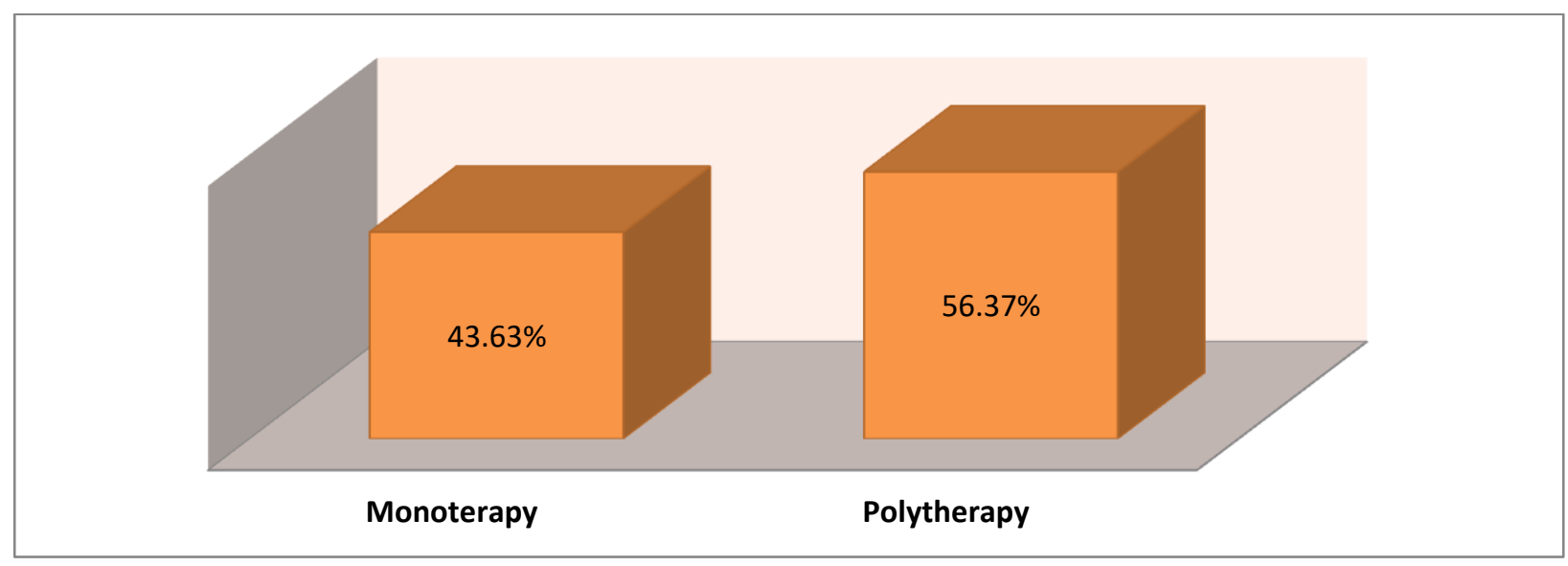

Figure 8- Distribution of antiepileptic drugs polytherapy according to drugs antiepileptic combination

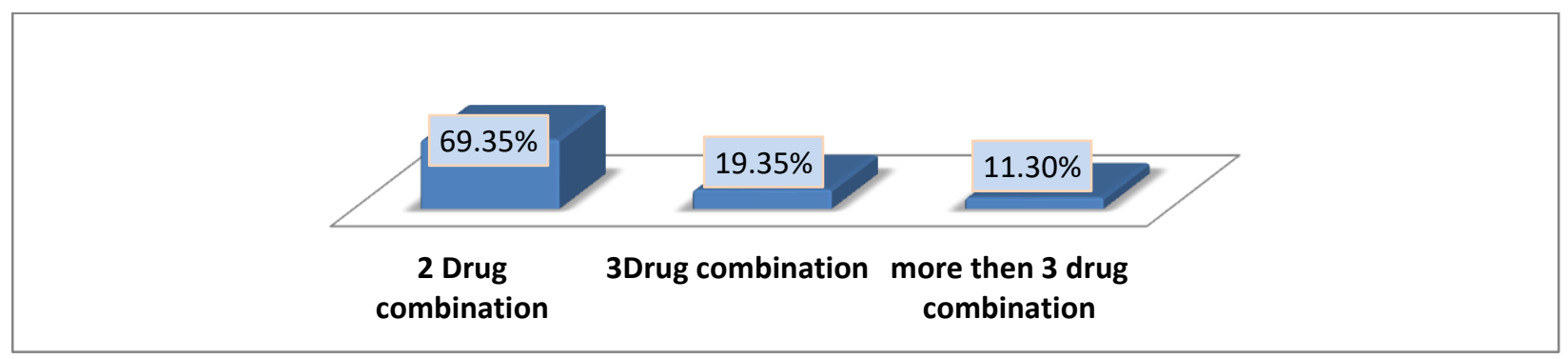

Figure 9- Distribution of antiepileptic drugs interaction

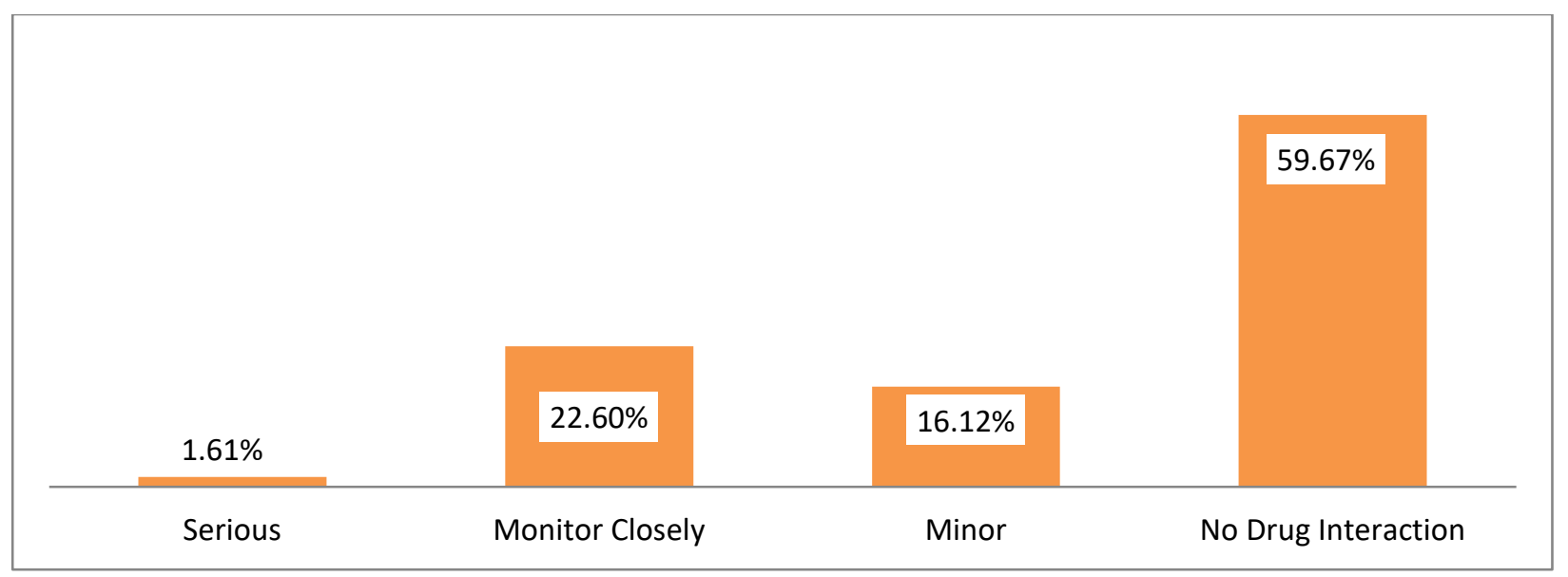

Figure 10- Distribution of most commonly prescribed antiepileptic drug 
International Journal of Research in Advent Technology, Vol.7, No.1, January 2019

E-ISSN: 2321-9637

Available online at www.ijrat.org

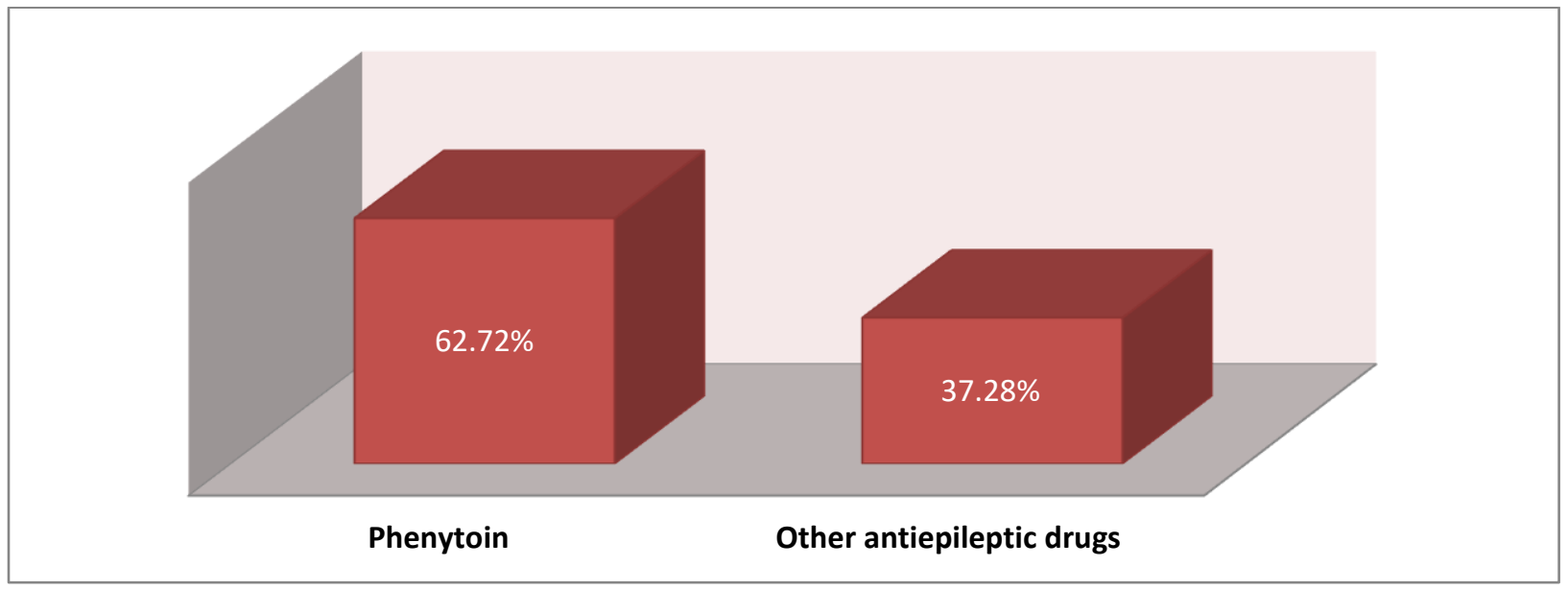

Figure 11 Distribution of seizure participants in different age group

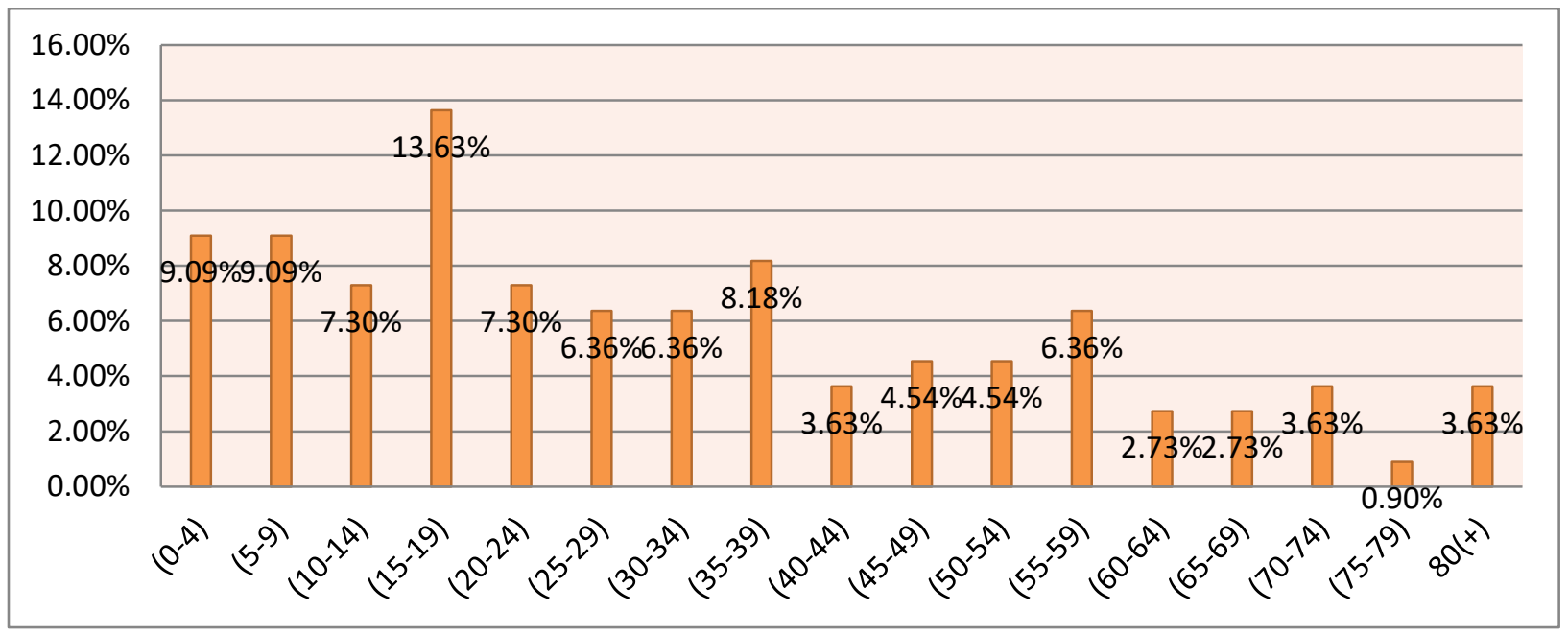

Figure 12- Distribution of antiepileptic drugs polytherapy according to rationality

\section{Irrational}

\section{Rational}

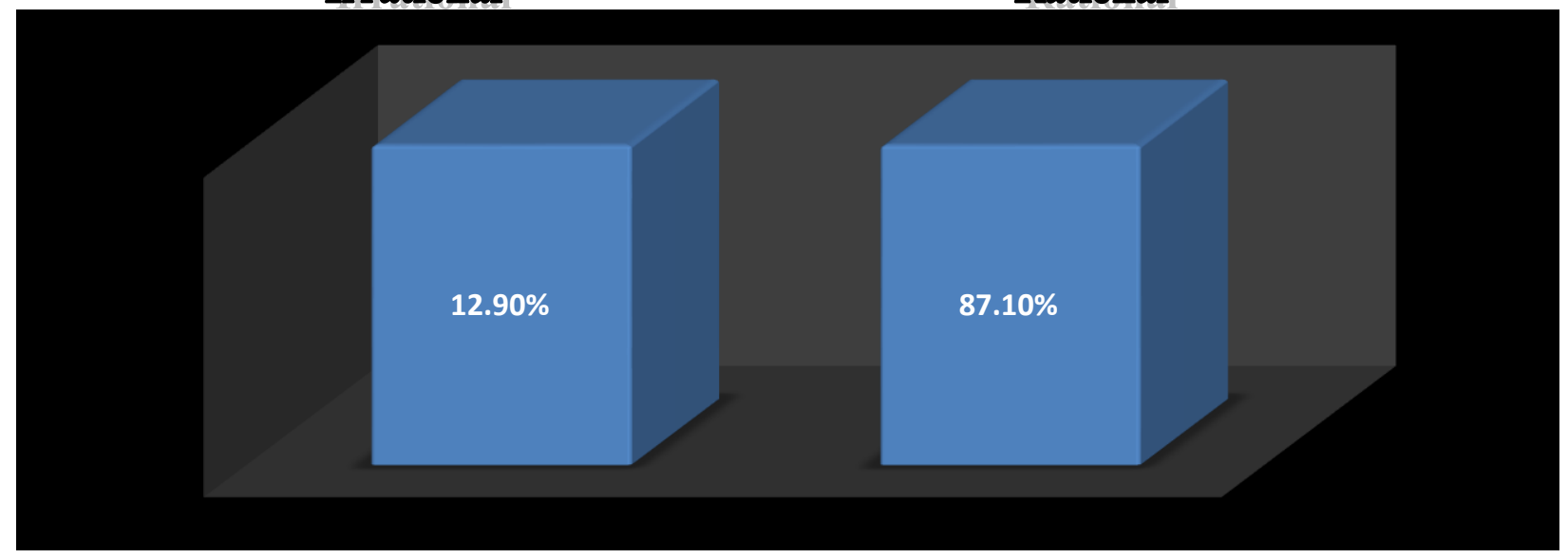


International Journal of Research in Advent Technology, Vol.7, No.1, January 2019 E-ISSN: 2321-9637

Available online at www.ijrat.org

\section{TABLES}

Table 1- distribution of subjects on the basis of gender

\begin{tabular}{|c|c|c|c|}
\hline S. No. & Gender & No. of Subjects & Percentage \% \\
\hline 1 & Male & 62 & $56 \%$ \\
\hline 2 & Female & 48 & $44 \%$ \\
\hline
\end{tabular}

Table 2- distribution of subjects on the basis of age status

\begin{tabular}{|c|c|c|c|}
\hline S. No. & Age Status & No. of Subjects & Percentage \% \\
\hline 1 & Below 18 years & 34 & 31 \\
\hline 2 & Above 18 years & 76 & 69 \\
\hline
\end{tabular}

Table 3 distribution of subjects on the basis of types of epilepsy

\begin{tabular}{|c|c|c|c|}
\hline S.No. & Type of epilepsy & No. of Subject & Percentage \% \\
\hline 1 & Status epilepsy & 2 & 6.36 \\
\hline 2 & Absence epilepsy & 7 & 37.27 \\
\hline 3 & Tonic clonic epilepsy & 30 & 32.73 \\
\hline 5 & Simple partial epilepsy & 36 & 31.82 \\
\hline
\end{tabular}

Table 4 -Distribution of prescribed antiepileptic drugs according to generation

\begin{tabular}{|c|c|c|}
\hline S. No. & Prescribed antiepileptic generation & Percentage \% \\
\hline 1 & First generation antiepileptic & 39.49 \\
\hline 2 & Second generation antiepileptic & \\
\hline
\end{tabular}


International Journal of Research in Advent Technology, Vol.7, No.1, January 2019 E-ISSN: 2321-9637

Available online at www.ijrat.org

Table 5- Distribution of antiepileptic drugs prescribed under first generation

\begin{tabular}{|c|c|c|}
\hline S. No. & First generation antiepileptic & Percentage \% \\
\hline 1 & Phenytoin & 66.35 \\
\hline 2 & Valproate & 21.16 \\
\hline 3 & Carbamazepam & 10.57 \\
\hline 4 & Phenobarbital & 1.92 \\
\hline
\end{tabular}

Table 6- Distribution of antiepileptic drugs prescribed under second generation

\begin{tabular}{|c|c|c|}
\hline S. No. & Second generation antiepileptic & Percentage \% \\
\hline 1 & Levetiracetam & 69.12 \\
\hline 2 & Diazepam & 2.94 \\
\hline 3 & Clonazepam & 8.82 \\
\hline 4 & Lorazepam & 16.18 \\
\hline 5 & Clonazepam & 2.94 \\
\hline
\end{tabular}

Table 7- Distribution of antiepileptic drugs according to monotherapy and polytherapy

\begin{tabular}{|c|c|c|c|}
\hline S. No. & Antiepileptic drug therapy & No of prescription & Percentage \% \\
\hline 1 & Monotherapy & 48 & 43.63 \\
\hline 2 & Polytherapy & 62 & 56.37 \\
\hline
\end{tabular}

Table 8- Aistribution of antiepileptic drugs polytherapy according to antiepileptic drugs combination

\begin{tabular}{|c|c|c|c|}
\hline S. No. & No. of antiepileptic drugs combination & $\begin{array}{c}\text { No. of } \\
\text { prescription }\end{array}$ & Percentage \% \\
\hline 1 & 2 drug combination & 43 & 69.35 \\
\hline 2 & 3 drugs combination & 12 & 19.35 \\
\hline 3 & More than 3 drug combination & 7 & 11.30 \\
\hline
\end{tabular}

Table 9- Distribution of number of antiepileptic drugs interaction

\begin{tabular}{|c|c|c|c|}
\hline S. No. & Type of drug interaction & No of prescription & Percentage \% \\
\hline 1 & Serious & 1 & 1.61 \\
\hline 2 & Monitor closely & 14 & 22.60 \\
\hline 3 & Minor & 10 & 16.12 \\
\hline 4 & No drug interaction & 37 & 59.76 \\
\hline
\end{tabular}


International Journal of Research in Advent Technology, Vol.7, No.1, January 2019 E-ISSN: 2321-9637

Available online at www.ijrat.org

Table 10- Distribution of most commonly prescribed antiepileptic drug

\begin{tabular}{|c|c|c|c|}
\hline S. No. & $\begin{array}{c}\text { Most commonly prescribed antiepileptic } \\
\text { drug }\end{array}$ & No of prescription & Percentage \% \\
\hline 1 & Phenytoin & 69 & 62.72 \\
\hline 2 & Other antiepileptic & 41 & 37.28 \\
\hline
\end{tabular}

Table 11- Distribution of seizure participants in different age group

\begin{tabular}{|c|c|c|c|}
\hline S. No. & Age group (year) & No of participants & Percentage \% \\
\hline 1 & $0-4$ & 10 & 9.09 \\
\hline 2 & $5-9$ & 10 & 9.09 \\
\hline 3 & $10-14$ & 8 & 7.30 \\
\hline 4 & $15-19$ & 15 & 13.63 \\
\hline 5 & $20-24$ & 8 & 7.30 \\
\hline 6 & $25-29$ & 7 & 6.36 \\
\hline 7 & $30-34$ & 7 & 6.36 \\
\hline 8 & $35-39$ & 9 & 8.18 \\
\hline 9 & $40-44$ & 4 & 3.63 \\
\hline 10 & $45-49$ & 5 & 4.54 \\
\hline 11 & $50-54$ & 5 & 4.54 \\
\hline 12 & $55-59$ & 7 & 6.36 \\
\hline 13 & $60-64$ & 3 & 2.73 \\
\hline 14 & $65-69$ & 3 & 2.73 \\
\hline 15 & $70-74$ & 4 & 3.63 \\
\hline 16 & $75-79$ & 1 & 0.90 \\
\hline 17 & $80(+)$ & 4 & 3.63 \\
\hline
\end{tabular}

Table 12- Distribution of antiepileptic drugs polytherapy according to rationality

\begin{tabular}{|c|c|c|c|}
\hline S. No. & Drug therapy of antiepileptic & No of prescription & \% \\
\hline 1 & Irrational & 8 & 12.90 \\
\hline 2 & Rational & 54 & 87.10 \\
\hline
\end{tabular}

